\title{
Chatbot Iara: relacionando e interagindo com dados sobre o novo coronavírus em Santa Cruz do Sul
}

\author{
Nicolas Fischer ${ }^{1}$, Patrick Martini ${ }^{2}$, Mateus Tomaz ${ }^{3}$, Patrick Priebe ${ }^{1}$, Matheus \\ Konrath $^{2}$, Maurício Konrath ${ }^{2}$, Daniela Bagatini ${ }^{1,2}$, Daniela Peranconi ${ }^{1,2}$ \\ ${ }^{1}$ Departamento de Engenharias, Arquitetura e Computação - Curso de Ciência da \\ Computação - Universidade de Santa Cruz do Sul (UNISC) - Santa Cruz do Sul - RS - \\ Brasil \\ ${ }^{2}$ Departamento de Engenharias, Arquitetura e Computação - Curso de Engenharia de \\ Computação - Universidade de Santa Cruz do Sul (UNISC) - Santa Cruz do Sul - RS - \\ Brasil
${ }^{3}$ Curso de Medicina - Universidade de Santa Cruz do Sul (UNISC) - Santa Cruz do Sul - RS - Brasil
\{nicolasfischer, plmartini, mateusarruda, matheusk3, mauriciokonrath, patrickpriebe\}@mx2.unisc.br, \{bagatini, danielap\}@unisc.br

\begin{abstract}
Realizing the need for mechanisms to facilitate the dissemination of information, in a simple way, about the pandemic about the coronavirus in Santa Cruz do Sul, this work presents Iara, a chatbot that lists quantitative data and information from municipal decrees. The assistant's development took place in three stages: (1) Data capture, curation and organization; (2) Planning of decisions and actions; (3) Agent construction, data inclusion and training. The chatbot is a prototype to identify the acceptance of bots on websites, which already provides a receptive view to actions triggered by the bot, validating the proposal to relate and allow users to interact with public data with the unit.
\end{abstract}

Resumo. Percebendo a necessidade de mecanismos para facilitar a disseminação das informações, de forma simples, acerca da pandemia sobre o coronavírus em Santa Cruz do Sul, esse trabalho apresenta a Iara, um chatbot que relaciona dados quantitativos e informações de decretos municipais. $O$ desenvolvimento do assistente ocorreu em três etapas: (1) Captação, curadoria e organização dos dados; (2) Planejamento das decisões e ações; (3) Construção do agente, inclusão dos dados e treinamento. O chatbot trata-se de um protótipo para identificar a aceitação de bots em sites, o qual já fornece uma visão receptiva a ações desencadeadas pelo bot, validando a proposta de relacionar e permitir que usuários interajam com dados públicos com unidade.

\section{Introdução}

Em dezembro de 2019 um surto de pneumonia viral surgiu na cidade de Wuhan, província de Hubei, na China, deixando as autoridades sanitárias internacionais em alerta. Devido sua rápida disseminação, a Organização Mundial da Saúde (OMS) declarou emergência de saúde global em janeiro de 2020. O vírus foi denominado "Síndrome Respiratória 
aguda grave Coronavírus 2" (SARS-CoV-2) e a patologia por ele ocasionada foi nomeada pela OMS de "doença coronavírus" (COVID-19), popularmente chamado novo coronavírus [World Health Organization 2020].

Segundo o Ministério da Saúde (2020) a transmissibilidade do vírus entre humanos ocorre pelo contato direto com uma pessoa infectada através de gotículas respiratórias expiradas e, mais raramente, através de fômites e aerossóis nos atendimentos médicos. Assim, a prevenção é mandatória para que a disseminação do vírus não seja ainda mais alarmante. Aconselha-se o distanciamento social de pelo menos 1 metro e meio, higiene respiratória (uso de máscara, cobrir boca e nariz ao tossir e espirrar, descartar o lenço após utilizá-lo em uma lixeira com tampa) e assepsia das mãos por, pelo menos, 20 segundos com água e sabão ou algum produto antisséptico a base de álcool [Beeching, Fletcher e Fowler 2020]. Por fim, manter o isolamento social, principalmente se apresentar sintomas gripais leves ou que remetam a sintomas da doença.

A comunidade científica mundial identificou que as cidades com maior trânsito populacional são as que mais sofrem na transmissão do vírus, já que recebem um fluxo de pessoas de origens distintas, que podem trazer a carga viral consigo. Nesse contexto, está a cidade de Santa Cruz do Sul, localizada no Vale do Rio Pardo no Rio Grande do Sul, que se caracteriza como uma cidade de forte importância regional, nacional e internacional por ser polo de produção e exportação de tabaco, ter um comércio de referência na região e ser uma cidade universitária. Mas, apesar do grande fluxo de pessoas, Santa Cruz do Sul apresentou o primeiro caso suspeito em 27 de fevereiro e o primeiro caso confirmado somente um mês depois, conforme dados da Secretaria Municipal de Saúde (SMS) [Sec. Mun. Saúde 2020].

Além dos dados quantitativos apresentados pela SMS, a Prefeitura de Santa Cruz do Sul tem orientado a população por meio de decretos municipais, que indicam recomendações, ações e instruções a serem tomadas pela comunidade e poder público. Porém, não existe um veículo digital (como um site Web) que entregue aos cidadãos dados sobre o coronavírus de forma dinâmica e relacione os números divulgados pela SMS com as decisões decretadas pelo prefeito. Assim, as informações são entregues à população por meio de boletins, notas publicadas de forma isoladas, em canais como o site da SMS ou veículos da imprensa local.

Neste sentido, proporcionar caminhos para relacionar dados quantitativos (como número de casos confirmados, recuperados, óbitos) e informações de decretos municipais (como orientações do horário de funcionamento do comércio e indústria), possibilita dar transparência e permitir aos cidadãos perceberem a unidade entre dados e decisões. Também se faz necessário disponibilizar o acesso às informações de maneira simples, facilmente compreendidas. "Em uma sociedade, em que o acesso à informação é 'necessário' em um espaço de tempo cada vez menor, as pessoas buscam por aplicações informatizadas para auxiliá-las (...)” [Carvalho Júnior e Carvalho 2018].

Dado o cenário apresentado, com o intuito de promover maior transparência dos dados numéricos divulgados da doença e das decisões tomadas pela Prefeitura, surge um questionamento: "Como relacionar dados quantitativos com as orientações dos decretos municipais sobre o coronavírus e possibilitar ao cidadão interagir com estas informações de maneira natural?". 
Para atingir o objetivo de relacionar e interagir com dados sobre o coronavírus em Santa Cruz do Sul, este trabalho apresenta o desenvolvimento do chatbot Iara. Entendemos um chatbot como um agente de software presente no ambiente digital que realiza ações desencadeadas pelo usuário [Cruz, Alencar e Schmitz 2018]. Especificamente, o chatbot Iara, prima por empregar ações de chat por meio de conversação com o usuário em linguagem natural, facilitando a comunicação e permitindo que o cruzamento de informações solicitadas pelo usuário possa ser interpretado de forma personalizada.

$\mathrm{Na}$ seção 2, apresentamos os procedimentos metodológicos, as etapas e a pesquisa. Na seção 3 exemplificamos a aplicação para o chatbot Iara, trazendo consecutivamente as considerações finais. $\mathrm{O}$ trabalho com suas seções, foi conduzido pelas principais referências bibliográficas, expostas na sua parte final.

\section{Procedimentos metodológicos}

A pesquisa desenvolvida é exploratória, pois realizamos um levantamento bibliográfico sobre chatbot que orientou este trabalho. Também é um estudo de caso, com a curadoria de dados e a construção da base de conhecimento do bot Iara sobre o coronavírus em Santa Cruz do Sul. Neste contexto, entendemos como contribuições, o tratamento, a organização e a utilização de métodos mistos, que permitem a relação entre dados qualitativos dos decretos e quantitativos dos números sobre o coronavírus (compreendemos métodos mistos em Santos et al. (2017) sob o termo "triangulação"1).

\subsection{Relacionando os dados}

O trabalho foi organizado em três etapas, conforme apresentamos nas subseções a seguir.

\subsubsection{Captação, curadoria e organização dos dados}

Para os dados quantitativos referentes a pandemia (número de casos confirmados, óbitos, recuperados etc.), optamos por utilizar o Painel Coronavírus RS [SES/RS, 2020], desenvolvido e atualizado pelo Governo do estado do Rio Grande do Sul, principalmente pela facilidade em utilizar os dados em formato de arquivo $\mathrm{CSV}^{2}$. Quanto às informações pertinentes aos decretos foi necessário a leitura manual dos documentos oficiais publicados no site da SMS. A fonte oficial garante a consistência dos dados, evitando que eventuais transcrições modifiquem a compreensão da informação, ou seja, permite que o chatbot possa interagir e entregar dados corretos ao usuário. A Figura 1 mostra o fluxo de representação deste processo.

\footnotetext{
${ }^{1}$ O termo "triangulação" representa, por exemplo, o "estudo híbrido", "pesquisa integrada/combinada". [SANTOS et al., 2017].

${ }^{2}$ CSV é uma sigla para Comma Separated Values, que denota um formato de arquivo onde os valores são separados por vírgula. Este tipo de arquivo é amplamente utilizado em áreas da Computação que trabalham com dados, como Engenharia/Ciência de Dados.
} 


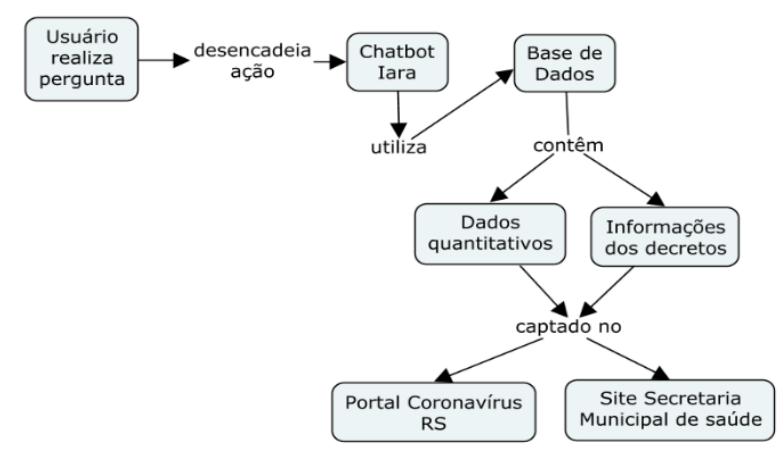

Figura 1 - Fluxo de representação dos dados

A base de dados mencionada na figura é a responsável por centralizar as informações do Painel Coronavírus RS (atualizadas automaticamente a cada 30 minutos) e dos decretos, sobre os quais realizou-se uma curadoria (site SEC). Essa base alimenta a base de conhecimento do chatbot Iara e, também, serve para o treinamento e o desenvolvimento das interações (ações e reações) do bot.

\subsubsection{Planejamento das decisões e ações}

Para a solução de chatbot foi utilizada a ferramenta DialogFlow, uma plataforma integrante dos serviços de computação em nuvem da Google, que permite a criação de assistentes virtuais empregando Processamento de Linguagem Natural (PLN).

Consideramos como primordial a atenção à formulação e elaboração de comportamentos do bot que possibilitem entregas de informações úteis e uma comunicação descomplicada com os usuários. Desta forma, antes de planejar as decisões e ações (intenções no DialogFlow) para o chatbot, optamos por realizar uma pesquisa por meio de um questionário disponibilizado na ferramenta Google Forms para conhecer a percepção dos usuários quanto ao uso de chatbot em sites.

Desta forma, convidamos à participação voluntária e não identificada, estudantes universitários de uma turma de primeiro semestre dos cursos de Computação, visto que assistentes virtuais era um dos tópicos de estudo e os participantes são potenciais usuários de chatbots. Obtivemos 11 (onze) respostas e a questão de maior impacto em nossa avaliação foi quanto à comunicação do chatbot, onde perguntamos: "Você considera importante um assistente virtual possuir traços na conversação que a torne dinamicamente mais próxima ao diálogo humano?"; os participantes sinalizaram "Sim, sem dúvida!" em 63,6\% das respostas. Com base na análise das respostas, efetuamos o planejamento das decisões e ações do chatbot. Para manter uma conversação dinâmica, ativa e estimular a compreensão, seguimos a estratégia de fazer com que perguntas e respostas continuamente desencadeiam outras, ou seja, novas perguntas e respostas.

\subsubsection{Construção do agente e inclusão dos dados e treinamento}

Para otimizar a inclusão das demais informações para o treinamento do chatbot, utilizamos a base de conhecimento da plataforma nativa do DialogFlow, a Knowledge. Portanto, as informações dos decretos estruturadas na base de dados, apresentadas na Figura 1, serviram para popular a base de conhecimento de mensagens pré-definidas do 
chatbot. Algumas informações sobre os decretos são: data, número, decisões, link para o decreto, rótulo (saúde, setor público, educação, transporte, indústrias/comércios).

\section{Chatbot Iara: exemplificando uma interação}

O chatbot Iara foi construído com o intuito de facilitar a interação dos usuários com as informações sobre o coronavírus em Santa Cruz do Sul. Nesta seção apresentamos um breve exemplo dessa interação.

Como exemplificado na Figura 2, ao realizar a chamada de ação, na área de inserção de texto, o usuário consegue interagir com o chatbot. A Iara busca a melhor resposta e a entrega ao usuário, procurando sempre manter a conversação ativa. Já, na Figura 3, a partir da manifestação de boas-vindas do chatbot, o usuário informa o que gostaria de saber e, desta forma, é guiado pelas interações do assistente. Supondo que o usuário queira saber os decretos relacionados a algum setor específico, basta ele indicar o setor (como "Educação") e a Iara apresenta informações correspondentes sobre os decretos neste contexto. $\mathrm{O}$ usuário ainda pode informar o número específico do decreto e a Iara irá exibir o que foi publicado no documento e o respectivo link para acessá-lo no site da Prefeitura. Desta forma, as perguntas realizadas pelo usuário ocasionam ações e eventuais reações do assistente, mas, também, o chatbot estimula a interação do usuário.

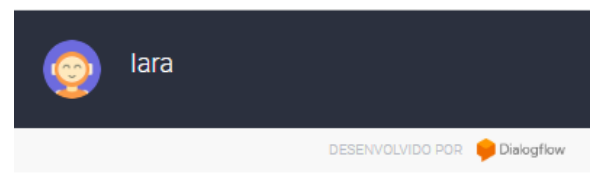

Olá. Gostaria de saber sobre o projeto.

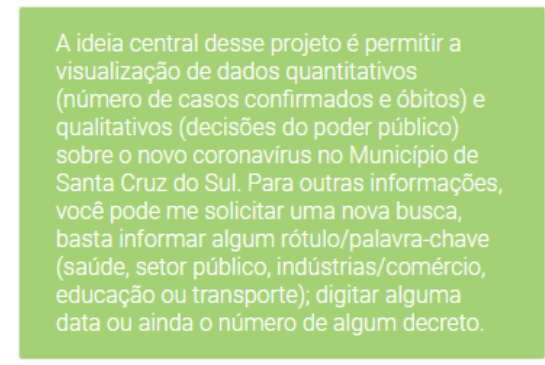

Diga alguma coisa

Figura 2 - Representação de uma ação tomada pelo agente

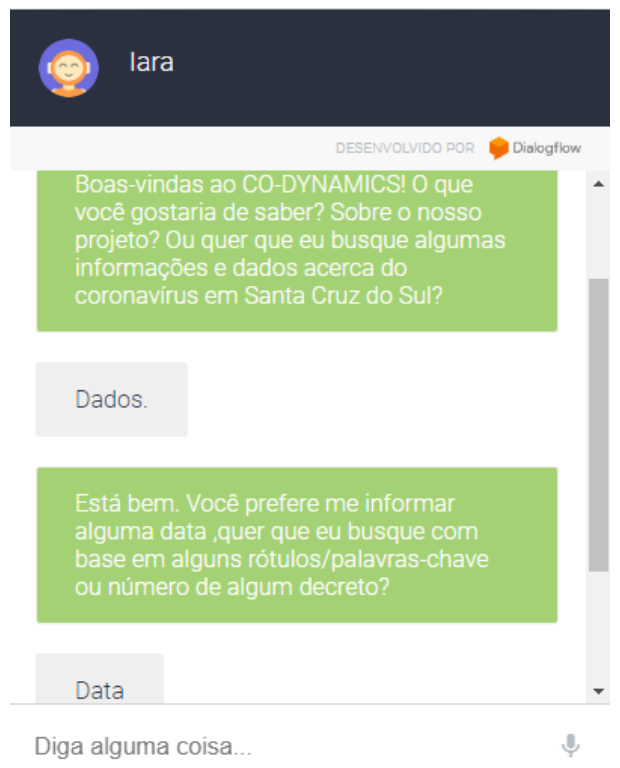

Figura 3 - Representação de uma reação tomada pelo agente

Mobilizada pela pergunta (entrada), as ações do assistente correspondem a busca na base de conhecimentos e sua resposta através de mensagens, como ilustrado na Figura 2. Já as reações são novas perguntas realizadas pelo chatbot com o intuito de filtrar as alternativas e personalizar ainda mais a ação. Estas últimas representam as intenções que retornam à seção onde geram opções para os desejos, conforme exemplificado na Figura 3. Assim, podemos notar que determinadas saídas podem ser utilizadas como entrada. 


\section{Considerações finais}

A facilidade de interação e a capacidade de conversação do chatbot Iara, em uma dinâmica de perguntas e respostas, possibilita que o usuário pesquise e obtenha informações sobre os decretos municipais combinados aos números sobre o coronavírus de forma transparente. Assim, neste artigo apresentamos o processo para relacionar dados e estratégias para a interação com estes. Acreditamos que a conversação em linguagem natural pode gerar um impacto positivo de interação e mobilizar a comunidade de Santa Cruz do Sul a manter-se vigilante sobre as informações do coronavírus.

O chatbot Iara, além de associar dados quantitativos e qualitativos, evidencia e alerta sobre as condições do coronavírus e as ações de enfrentamento das autoridades públicas. Também permite que o usuário busque as informações em um único lugar. Esta unidade e simplicidade pode auxiliar e mobilizar as pessoas a refletir sobre as condições e o combate da doença. Portanto, com este trabalho, destacamos a importância de criarmos meios para que a informação possa ser disseminada de maneira "natural", de forma que, para o usuário final, a tarefa de obter informações seja simples, rápida e atrativa. Destacamos que aplicações como a que propomos, de conversação e integração de dados, para modalidades de dados distintos, podem ser aplicadas em diferentes contextos e colaborar para o fomento de soluções computacionais.

Como trabalhos futuros, pretende-se adicionar novos dados, como casos em acompanhamento e número de pessoas recuperadas; encontrar formas que permitam automatizar os dados obtidos nos decretos; e, disponibilizar o chatbot Iara para usuários finais.

\section{Referências}

Beeching, Nicholas, Tom Fletcher, e Robert Fowler. "Doença do coronavírus 2019 (COVID-19)". BMJ best practice, BMJ Publishing Group Ltd 2020, 2020, 179.

Carvalho Júnior, Ciro Ferreira, e Kely Rejane Souza dos Anjos de Carvalho. "Chatbot: uma visão geral sobre aplicações inteligentes.” In: Revista sítio novo, 2018: 68-70.

Cruz, Leôncio Teixeira, Antonio Juarez Alencar, e Eber Assis Schmitz. "Assistentes Virtuais Inteligentes e Chatbots: um guia prático e teórico sobre como criar experiências e recordações encantadoras para os clientes da sua empresa". 1a . Edição: Sergio Martins Oliveira. Vol. I. Rio de Janeiro: Brasport, 2018.

Santos, José Luís Guedes, Alacoque Lorenzini Erdmann, Betina Hörner Schlindwein Meirelles, Gabriela Marcellino Melo Lanzoni, Viviane Pecini Cunha, e Ratchneewan Ross. "Integração entre dados quantitativos e qualitativos em uma pesquisa de métodos mistos." In: SciELO 26, no 3 (2017).

Secretaria da Saúde do Estado do Rio Grande do Sul (SES/RS). "Painel Coronavírus RS". 2020. https://ti.saude.rs.gov.br/covid19/ (acesso em 06 de 09 de 2020).

Secretaria Municipal de Saúde. "Coronavírus". 2020. https://www.santacruz.rs.gov.br/conteudo/coronavirus (acesso em 29 de Agosto de 2020).

World Health Organization. "Coronavirus". s.d. https://www.who.int/healthtopics/coronavirus\#tab=tab_3 (acesso em 29 de Março de 2020). 